FILIZOLA, G. J.; BOTELHO, D. M.;

Lei 10.639/2003: caminhos para desconstrução do racismo epistêmico/religioso no ambiente escolar

ARTIGOS

\title{
Lei 10.639/2003: caminhos para desconstrução do racismo epistêmico/religioso no ambiente escolar
}

Gustavo Jaime Filizola

$U F P E-R E C I F E-P E$

ORCID:0000-0003-0458-6830

Denise Maria Botelho

UFRPE - RECIFE-PE

RESUMO: O objetivo deste artigo é discutir a importância da Lei no 10.639/2003 como meio de desconstrução do epistêmico/religioso ${ }^{1}$ nas escolas e a importância do trabalho interdisciplinar para a implementação da mesma. Faremos uma breve retrospectiva da implantação e implementação da Lei n 10.639/2003 e discutiremos o Candomblé como religiões que articulam conhecimentos e diferentes formas religiosas advindas do continente africano. Elencamos alguns livros e artigos para ajudar docentes a trabalharem a temática afro-brasileira e temas relacionados às religiões de Matriz Africana na escola.

PALAVRAS-CHAVE: Lei nº. 10.639/2003; racismo epistêmico/religioso, ensino religioso; interdisciplinaridade.

\section{Law 10.639/2003: Pathways for developing epistemic/religious racism in the school environment}

\begin{abstract}
The purpose of this article is to discuss the importance of Law No. 10,639 / 2003 as a means of deconstructing the epistemic / religious in schools and the importance of interdisciplinary work for its implementation. We will briefly review the implementation and implementation of Law No. 10,639 / 2003 and discuss Candomblé as religions that articulate knowledge and different religious forms from the African continent. We have compiled some books and articles to help teachers work on Afro-Brazilian themes and issues related to African Matrix religions at school.
\end{abstract}

KEYWORDS: Law no. 10,639 / 2003; epistemic / religious racism, religious education; interdisciplinarity. 


\section{autêntica}

\section{Ley 10.639/2003: caminos para el desarrollo del racismo epistémico/religioso en el entorno escolar}

RESUMEN: El propósito de este documento es discutir la importancia de la Ley N 10.639 / 2003 como un medio para deconstruir a los epistémicos / religiosos en las escuelas y la importancia del trabajo interdisciplinario para su implementación. Revisaremos brevemente la implementación y la implementación de la Ley $N^{\circ} 10.639$ / 2003 y discutiremos el Candomblé como religiones que articulan el conocimiento y las diferentes formas religiosas del continente africano. Hemos compilado algunos libros y artículos para ayudar a los maestros a trabajar sobre temas y temas afrobrasileños relacionados con las religiones de la Matriz africana en la escuela.

PALABRAS- CLAVE: Ley núm. 10.639 / 2003; racismo epistémico / religioso, educación religiosa; interdisciplinariedad. 


\section{autêntica}

DOI https://doi.org/10.31639/rbpfp.v\%vi\%i.251

\section{CONSIDERAÇÕES INICIAIS}

Vivemos em uma sociedade estruturada e estruturante a partir do racismo. Podemos encontrá-lo desde a formação da política educacional brasileira até na forma que a escola lida com os conhecimentos afrodescendentes. Paradoxalmente, sociedade essa que ao mesmo tempo não o reconhece e sabe que ele existe. Ele é alimentado cotidianamente, quando passamos a olhar o espaço social apenas pelo olhar hegemônico, ou seja, perceber os indivíduos a partir do olhar de grupos privilegiados. Se não ampliarmos a percepção para outras formas de ser, para outras epistemologias, ficará muito difícil haver alguma mobilização para diminuir o racismo na sociedade.

Os currículos escolares brasileiros e a prática docente nas escolas estão fundamentados numa perspectiva eurocêntrica. Quijano (2009, p. 112), ao explicar as implicações mais importantes da hegemonia do eurocentrismo nas relações culturais em geral, diz que "[...] em todo o mundo eurocentrado foi se impondo a hegemonia do modo eurocêntrico de percepção e produção do conhecimento e numa parte muito ampla da população mundial o próprio imaginário foi demonstradamente colonizado".

Miguel Arroyo $(2010,2015)$ e Boaventura de Sousa Santos $(2001,2009)$ comungam da mesma ideia quando informam que o conhecimento produzido na escola é hierarquizado, seja no sentido do currículo amplo, seja no sentido dos conteúdos que estão estabelecidos nos currículos particularizados. Essa hierarquia também leva à negação, à inferiorização e à exclusão os conhecimentos que fogem dessa linha. O currículo, segundo esses autores, está também no campo da disputa, resultando na negação de algumas formas de conhecimento. A disputa originada da relação de colonialismo e de colonialidade, de subalternização, fez com que os conhecimentos dos grupos que foram colonizados aqui no Brasil, dos negros, índios, dos trabalhadores rurais fossem negados e silenciados no espaço escolar.

Podemos questionar por que apenas os conhecimentos que formam o currículo escolar são válidos? Por que o currículo formal do ensino exclui ou invisibiliza outras formas de saberes que podem/poderiam integrar o currículo formal? E pensarmos também, como os conhecimentos escolares foram historicamente produzidos? Por que se privilegia uma matriz epistêmica europeia e as de outros continentes não? Questionarmos dessa forma é tentar compreender e entender a história da educação no Brasil, história essa pautada numa lógica da desigualdade, da exclusão e do silenciamento.

\section{EUROCENTRISMO E ETNOCENTRISMO}

No Brasil, estamos vivendo um período político cada vez mais marcado pela exclusão social, uma lógica do capitalismo cada vez mais excludente. Santos $(2001,2009)$ coloca-se frontalmente contrário a essa perspectiva, discorda dessa situação que, para ele, leva-nos ao processo de desumanização. É um sentimento de indignação a qualquer processo de colonização que leve a desqualificação do outro.

Essa nova epistemologia trazida por esse sociólogo vai de encontro a essa linha que foi posta pela modernidade através da colonização, que separou a ciência de outros conhecimentos que não obedeciam aos critérios científicos de verdade. Essa linha que é uma forma de desqualificar tudo aquilo que está posto do outro lado, como expressão da não civilização, do subumano ou não-humano. Essa linha divisória é uma forma de fazer seres e epistemologias serem silenciadas, é uma forma de desqualificação do discurso do negro, do índio, do feminino, do homossexual, dos transexuais, etc. 


\section{autêntica}

DOI https://doi.org/10.31639/rbpfp.v\%vi\%i.251

Esse ideal de superioridade está apoiado na imagem de superioridade epistemológica, étnico-racial, linguística, geográfica, religiosa dos europeus, imagem essa criada por eles mesmos, tomando como base o ideal de civilidade. Esses ideiais foram espalhados pelo resto do mundo através da colonização e que continua na colonialidade. Ambas são ideias distintas.

Anibal Quijano (1992) e Ramón Grosfoguel (2009) pensam de forma semelhante ao diferenciar colonialismo² de colonialidade. Grosfoguel (2006, p. 53), informa que "Colonialidade e modernidade constituem duas faces de uma mesma moeda". Seguindo os passos de Quijano, Grosfoguel usa a designação "colonialidade" para se referir a situações coloniais da atualidade, onde as administrações coloniais foram praticamente erradicadas do sistema-mundo-capitalista, persistindo a opressão/ exploração cultural, política, sexual e econômica de grupos étnicos/ racializados que são subordinados por parte de grupos étnicos-raciais dominantes, com ou sem a existência de administrações coloniais.

Dentro desse processo de colonialismo e colonialidade encontramos duas expressões que diretamente se relacionam com esse processo: eurocentrismo e etnocentrismo.

Eurocentrismo é a teoria que colocou o pensamento europeu em um patamar superior às outras civilizações não europeias. Quijano (2005) faz uma relação da ideia do eurocentrismo ao do etnocentrismo, indicando características étnico-raciais nas manifestações eurocêntricas.

Para compreensão do racismo epistêmico/religioso, outro conceito importante é o do etnocentrismo que, segundo Fernandes (2017, p. 126),

[...] é caracterizado pelo tratamento do próprio grupo como medida dos demais grupos e por hierarquizar os outros como inferiores. No entanto, preconceito e etnocentrismo situam-se em campos conceituais diferentes, sendo a especificidade do etnocentrismo a valoração do outro pelas coordenadas de seu próprio grupo, mas não necessariamente uma valoração negativa.

Como consequência dessa percepção, a Europa se colocou como elemento fundamental na constituição da sociedade moderna e protagonista da história da humanidade. As diferenças biológicas, culturais, religiosas, epistemológicas, etc. dos "outros povos" que estivessem na "linha abaixo" desse eixo, foram classificadas como inferiores e bárbaras, gerando preconceitos e discriminações sobre esses povos.

Segundo Quijano (1995, p. 4) "el racismo y el etnicismo fueron inicialmente producidos em América y reproducidos después em el resto del mundo colonizado, como fundamentos de la especificidade de las relaciones de poder entre Europa y las poblaciones del resto del mundo".

Assim a ideia de raça foi utilizada dentro da América tendo como objetivo legitimar a dominação que foi imposta pela Europa. Raça foi um critério de divisão entre europeus e não europeus, cristãos e não-cristãos.

\section{DO EPISTEMICÍDIO}

Consideramos o sociólogo português Boaventura de Souza Santos como um dos importantes intelectuais para os debates sobre a educação no momento atual. Neste artigo destacamos sua ideia de que o pensamento moderno tem um caráter abissal, assim como a ideia do pensamento pós-abissal como um saber ecológico.

2 Neste artigo tomamos a ideia de colonialismo a partir de Quijano (2005) que exemplifica como sendo o domínio político-econômico de alguns povos sobre outros. É algo anterior à colonialidade. Há uma relação entre os dois termos, já que a colonialidade não teria sido possível historicamente sem o específico colonialismo imposto ao mundo a partir do final do século XV. 


\section{autêntica}

DOI https://doi.org/10.31639/rbpfp.v\%vi\%i.251

Para Santos (2009, p. 71) o dispositivo abissal do pensamento moderno:

Consiste num sistema de distinções visíveis e invisíveis, sendo que estas últimas fundamentam as primeiras. As distinções invisíveis são estabelecidas por meio de linhas radicais que dividem a realidade social em dois universos distintos: o "deste lado da linha" e o "do outro lado da linha". A divisão é tal que "o outro lado da linha" desaparece como realidade, torna-se inexistente e é mesmo produzido como inexistente. Inexistência significa não existir sob qualquer modo de ser relevante ou compreensível.

Ele coloca que esse raciocínio impossibilita a copresença dos dois lados da linha, em especial, quando se trata da área do conhecimento. Portanto, para Santos (p.85-86) a ideia do pensamento pós-abissal como um saber ecológico, se baseia na premissa de que há uma "inesgotável diversidade epistemológica do mundo" e no "reconhecimento da existência de uma pluralidade de formas de conhecimento além do conhecimento científico".

A partir desse conceito, ele passa a se interessar por um tipo de abordagem que diga: nós precisamos ver o outro, entender o outro que historicamente foi dominado, inferiorizado, colonizado pela cultura moderna, cultura do norte, uma cultura ocidental.

Ele radicaliza e passa a dialogar com outras formas de conhecimentos, com outras abordagens, que segundo ele, normalmente são silenciadas e colocadas em outro lado, o lado dos excluídos, dos inferiorizados, dos anulados e dos esquecidos, tais como a cultura negra, a cultura indígena, mas que também poderíamos incluir a cultura LGBTs, entre outras.

Segundo Santos (2001, p. 18),

O conhecimento científico cometeu muitos epistemicídios, produziu muita morte de conhecimentos alternativos. Precisamos denunciar esse epistemicídio e de recuperar na medida do possível os conhecimentos alternativos. Ao contrário do que proclamam os arautos da globalização o mundo é cada vez mais diverso e nessa diversidade emergem novas formas de conhecimento. Por outro lado, a ciência, ela própria é multicultural.

De acordo com Santos, essa outra leitura do mundo é importante, pois, mesmo que a colonização tenha chegado ao seu fim, no interior desses países que foram colonizados, continua-se a perceber o mundo na perspectiva da forma que o colonizador deixou.

O projeto colonizador, desde o século XVI, funcionou e funciona como um mecanismo de colonialidade da dominação da cultura e de uma epistemologia branca, europeia, sobre os demais componentes étnicos e raciais que se afastam dessa lógica. A própria reinterpretação desses países significa o rompimento daquilo que se cristalizou como forma de interpretação daquilo que nós somos, ou seja, quando Santos $(2001,2009)$ fala das epistemologias do Sul, ele não está se referindo exclusivamente aos países da América do Sul, mas também está incluindo os países africanos, da mesma forma quando ele se refere ao norte não está se referindo exclusivamente à Europa, mas também aos Estados Unidos.

Essa forma hegemônica de interpretar o mundo é que alimenta a desigualdade entre os diferentes. Dentro dessa lógica, vemos, até hoje, resultante do projeto colonizador, uma grande valorização dos conhecimentos, 


\section{autêntica}

DOI https://doi.org/10.31639/rbpfp.v\%vi\%i.251

da religiosidade e cultura europeia em detrimento das culturas indígenas, africanas, ciganas e de outras etnias. Assim, o epistemicídio é uma forma de entender a destituição da racionalidade, religiosidade, da cultura, da sexualidade e civilidade do outro.

Santos $(2001,2009)$ alerta sobre a importância dos movimentos sociais diante desse processo de anulação e desqualificação do outro. Também explicita a importância da academia de dialogar com esses grupos que formam tais movimentos, como os negros e as negras, os grupos indígenas, os trabalhadores rurais, etc., grupos que, ao vivenciarem processos de exclusão, perceberam a necessidade de produzirem outras formas de saberes. É isso que Santos passou a chamar de perspectiva de ecologia dos saberes.

O que analisaremos a seguir é o processo de implantação da Lei n. 10.639/2003, pois a mesma, além de ser fruto de anos de luta do movimento negro, é uma tentativa de desconstrução do racismo epistêmico. Uma forma de respeitar e aprender com outras epistemologias além daquelas que foram hegemonicamente estabelecidas.

A Lei n’. 10.639/2003 informa em seu Artigo 26-A: "Nos estabelecimentos de ensino fundamental e médio, oficiais e particulares, torna-se obrigatório o ensino de História e Cultura Africana e Afro-Brasileira ${ }^{3 "}$. Após 15 anos de sua implantação, ainda se percebe uma resistência para que ocorra sua introdução nos currículos escolares e aplicabilidade em sala de aula como forma de contribuir na desconstrução da falácia do mito da democracia racial, para igualdade racial no Brasil e na construção de uma justiça epistemológica e social, enfim, contribuir na construção de uma democracia real, onde negros, índios, brancos, ou seja, todos os cidadãos e todas as cidadãs possam viver o exercício pleno da democracia.

A Lei n.10.639/2003, é um caminho de desconstrução do racismo epistêmico/religioso no ambiente escolar, pois como afirma Santana (2010, p. 154) a Lei no. 10.639/2003 apresenta-se como:

possibilidade concreta na construção da cidadania, na medida em que estabelece pontos de convergências à oportunidade para o diálogo, seja no campo das subjetividades, seja no campo das interculturalidades. Essa aproximação cria vários caminhos para se pensar a erradicação do racismo em nossa sociedade. Desse modo, a lei permite essa possibilidade, o repensar as formas de convivência com o diferente a partir da perspectiva do respeito e da intolerância da discriminação racial ou de qualquer forma de preconceito correlato.

Assim, trabalhar com a Lei $n^{\circ}$. 10.639/2003 é uma forma de diminuir o preconceito e a discriminação em relação aos conhecimentos trazidos pelos negros e negras escravizadas, em especial, no que se refere às religiões afro-brasileiras na escola.

\section{BREVE RETROSPECTIVA DA IMPLANTAÇÃO E IMPLEMENTAÇÃO DA LEI Nº ${ }^{\circ}$ 10.639/20034}

A Lei $n^{\circ}$. 10.639/2003, como vitória do Movimento Negro Brasileiro contra o Racismo, foi homologada no dia 09 de janeiro de 2003 pelo então presidente da república Luiz Inácio Lula da Silva. Esse decreto alterou a Lei n 9.394, de 20 de dezembro de 1996, que estabelecia as diretrizes e bases da educação nacional, para incluir no currículo oficial da Rede de Ensino a obrigatoriedade da temática "História e Cultura Afro-Brasileira".

3 Disponível em http://www.planalto.gov.br/CCivil_03/leis/2003/L10.639.htm. Acesso em 08 jun.2019.

4 Devido ao espaço limitado do artigo, iremos apenas citar algumas implementações que dialoguem como nosso texto. 


\section{autêntica}

DOI https://doi.org/10.31639/rbpfp.v\%vi\%i.251

Outras resoluções irão acontecer ao longo de sua trajetória. Assim como assevera Silva (2017, p.154),

O primeiro desdobramento provocado pela Lei $n^{\circ} .10 .639 / 2003$ foi o Parecer 003/2004, do Conselho Nacional de Educação $(\mathrm{CNE})^{5}$, o qual dá uma série de contornos ao tema relações raciais no âmbito escolar, disciplinando temas, apresentando metodologias e elencando determinações.

Mais adiante, ampliando os espaços, do ensino fundamental e médio para também o ensino superior, citamos a resolução 01/2004, também oriunda do $\mathrm{CNE}^{6}$, que diz em seu Art. $1^{\circ}$ parágrafo $1^{\circ}$ :

As Instituições de Ensino Superior incluirão nos conteúdos de disciplinas e atividades curriculares dos cursos que ministram, a Educação das Relações Étnico-Raciais, bem como o tratamento de questões e temáticas que dizem respeito aos afrodescendentes, nos termos explicitados no Parecer CNE/CP 3/2004.

Continuando a caminhada, um outro desdobramento que citamos é o Estatuto da Igualdade Racial, Lei n. 12.288/20107 que vem fortalecer o teor apresentado pela Lei n . 10.639/2003. Em seu Art.11 parágrafo 1, assevera que "Os conteúdos referentes à história da população negra no Brasil serão ministrados no âmbito de todo o currículo escolar, resgatando sua contribuição decisiva para o desenvolvimento social, econômico, político e cultural do País". Esse item ressalta a contribuição que os afrodescendentes deram para a construção da sociedade brasileira em várias áreas do conhecimento e das artes.

Ainda destacamos as Diretrizes Curriculares Nacionais para a Educação das Relações Étnico-raciais e para o Ensino de História e Cultura Afro-Brasileira e Africana (Resolução $n^{\circ} .001 / 04^{8}$ ) que tem como objetivo orientar a implementação da Lei $n^{\circ}$. 10.639/2003 com a distribuição de exemplares para professores e professoras. Em seu Art. $2^{\circ}$ informa:

As Diretrizes Curriculares Nacionais para a Educação das Relações Étnico-Raciais e para o Ensino de História e Cultura Afro-Brasileira e Africana constituem-se de orientações, princípios e fundamentos para o planejamento, execução e avaliação da Educação, e têm por meta, promover a educação de cidadãos atuantes e conscientes no seio da sociedade multicultural e pluriétnica do Brasil, buscando relações étnico-sociais positivas, rumo à construção de nação democrática.

Por fim, citamos o Plano Nacional de Implementação das Diretrizes Curriculares Nacionais da Educação das Relações Étnico-Raciais e para o Ensino de História e Cultura Afro-Brasileira e Africanå que tem como objetivo fortalecer e institucionalizar as orientações que já existiam com o estabelecimento de metas e de estratégias para a execução da Lei n. 10.639/2003; delimitação de responsabilidades dos atores governamentais; proposições de ações de formação de professores; sensibilização de gestores; e produção de material didático.

5 Disponível em: http://portal.mec.gov.br/dmdocuments/cnecp_003.pdf. Acesso em 08 jun.2019.

6 Disponível em: http://portal.mec.gov.br/cne/arquivos/pdf/res012004.pdf. Acesso em 08 jun. 2019.

7 Disponível em: http:/www.planalto.gov.br/CcIVIL_03/_Ato2007-2010/2010/Lei/L12288.htm. Acesso em 08 jun. 2019.

8 Disponível em: http://portal.mec.gov.br/cne/arquivos/pdf/res012004.pdf. Acesso em 08 jun.2019.

9 Disponível em: http://portal.mec.gov.br/index.php?option=com_docman\&view=download\&alias=10098-diretrizes-curriculares\&Itemid=30192. Acesso em 08 jun.2019. 


\section{autêntica}

DOI https://doi.org/10.31639/rbpfp.v\%vi\%i.251

Com a promulgação e implementação da Lei n. 10.639/2003, muitos trabalhos com temáticas referentes às relações étnico-raciais foram produzidos ao longo desses anos10. Utilizá-los é uma questão de vontade política dos gestores e das gestoras, professores e professoras para trazerem referenciais positivos quanto à África e seus descendentes para a prática de sala de aula.

\section{ALGUMAS PEDRAS NO CAMINHO}

Os candomblés são religiões brasileiras que articulam conhecimentos de diferentes formas religiosas advindas do continente africano durante a diáspora negra e oferecem uma maneira particular de interpretação do mundo, que enfatiza a ligação com a história da própria comunidade, a ancestralidade e a negociação dos espaços de intervenção com o próprio sagrado (BOTELHO; NASCIMENTO, 2012).

A religião afro-brasileira marca presença no cenário das religiões existentes no Brasil. Os povos bantos tiveram participação importante nessa conjuntura. Essa etnia africana até o século XVIII predominava, depois vieram os sudaneses que passaram a predominar no século XIX.

Sobre as nações africanas que aqui chegaram, esclarece Mattos (2009) que com a intensificação do comércio dos/das escravizados/as, os europeus passaram a identificar os diferentes grupos africanos por 'nações' como: minas, angolas, moçambiques, jejes, cabindas, entre outras. Essa classificação dos grupos, segundo ela, costumava ser feita, em alguma localidade na África, na ocasião do batismo do africano. "Os povos de língua iorubá (sudaneses) foram os que forneceram ao candomblé sua infraestrutura de organização influenciada pelas demais contribuições dos demais grupos étnicos. Desse modo resultaram os dois modelos de cultos mais praticados: o rito jeje-nagô e o angola" (SILVA, 2005, p. 65).

Podemos dizer que o racismo religioso que recai sobre as religiões de matriz africana se dá por as colocarem abaixo de uma linha (SANTOS, 2001; 2008), imposto pelo projeto sistema-mundo capitalista, patriarcal, cristão, moderno, colonial, europeu (GROSFOGUEL, 2009) que se perpetua desde o século XVI até os dias atuais. São as formas coloniais de dominação (GROSFOGUEL, 2009; QUIJANO, 1992) que permanecem mesmo que tenha se encerrado o colonialismo.

Essas formas de colonialidade se fazem presentes nos processos de formação, enquanto estudantes, fomos e somos educados para relacionar tudo aquilo que está ligado ao candomblé como "coisas de negro", "do diabo" e "de macumba".

Essa ideia é reforçada pela bancada evangélica e as igrejas de religiões cristãs, em especial, as neopentecostais, que preenchem os espaços periféricos dos grandes centros urbanos de nosso país, continuam realizando o projeto de colonialidade, que foi instalado na modernidade, realizando um trabalho que objetiva anular, descaracterizar e inferiorizar as religiões de matrizes afro-indígenas.

Para comprovar os impactos negativos do neopentecostalismo para uma convivência respeitosa entre religiosos, trago os dados do Relatório sobre Intolerância e Violência Religiosa no Brasil (2011-2015): resultados

10 Entre outros trabalhos destacamos: Educação anti-racista: caminhos abertos pela Lei Federal no 10.639/03/ Secretaria de Educação Continuada, Alfabetização e Diversidade.-Brasília: Ministério da Educação, Secretaria de Educação Continuada, Alfabetização e Diversidade, 2005.; GOMES, Nilma Lino. Diversidade étnico-racial e educação no contexto brasileiro: algumas reflexões. In: GOMES, Nilma Lino (Org.). Um olhar além das fronteiras: educação e relações raciais. Belo Horizonte: Autêntica, 2007. ; MUNANGA, Kabengele. Superando o racismo na escola. 2. ${ }^{\text {a }}$ edição revisada, Brasília - Ministério da Educação, Secretaria de Educação Continuada, Alfabetização e Diversidade - (SECAD), 2008.; GOMES, Nilma Lino (org). Práticas pedagógicas de trabalho com relações étnico-raciais na escola na perspectiva da Lei no 10.639/03. Brasília: MEC/Unesco, 2012.; SANTOS, Erisvaldo Pereira dos. Formação de professores e religiões de matrizes africanas: um diálogo necessário. 2.ed. Belo Horizonte: Editora NANDYALA, 2015. 


\section{autêntica}

DOI https://doi.org/10.31639/rbpfp.v\%vi\%i.251

preliminares (2016), a partir da análise de matérias de jornais que trataram de intolerância e de violência religiosas, a maioria das vítimas nas reportagens são de religiões de Matrizes Africanas.

\section{GRÁFICO 1 - RELIGIÃO DAS VÍTIMAS NAS REPORTAGENS}

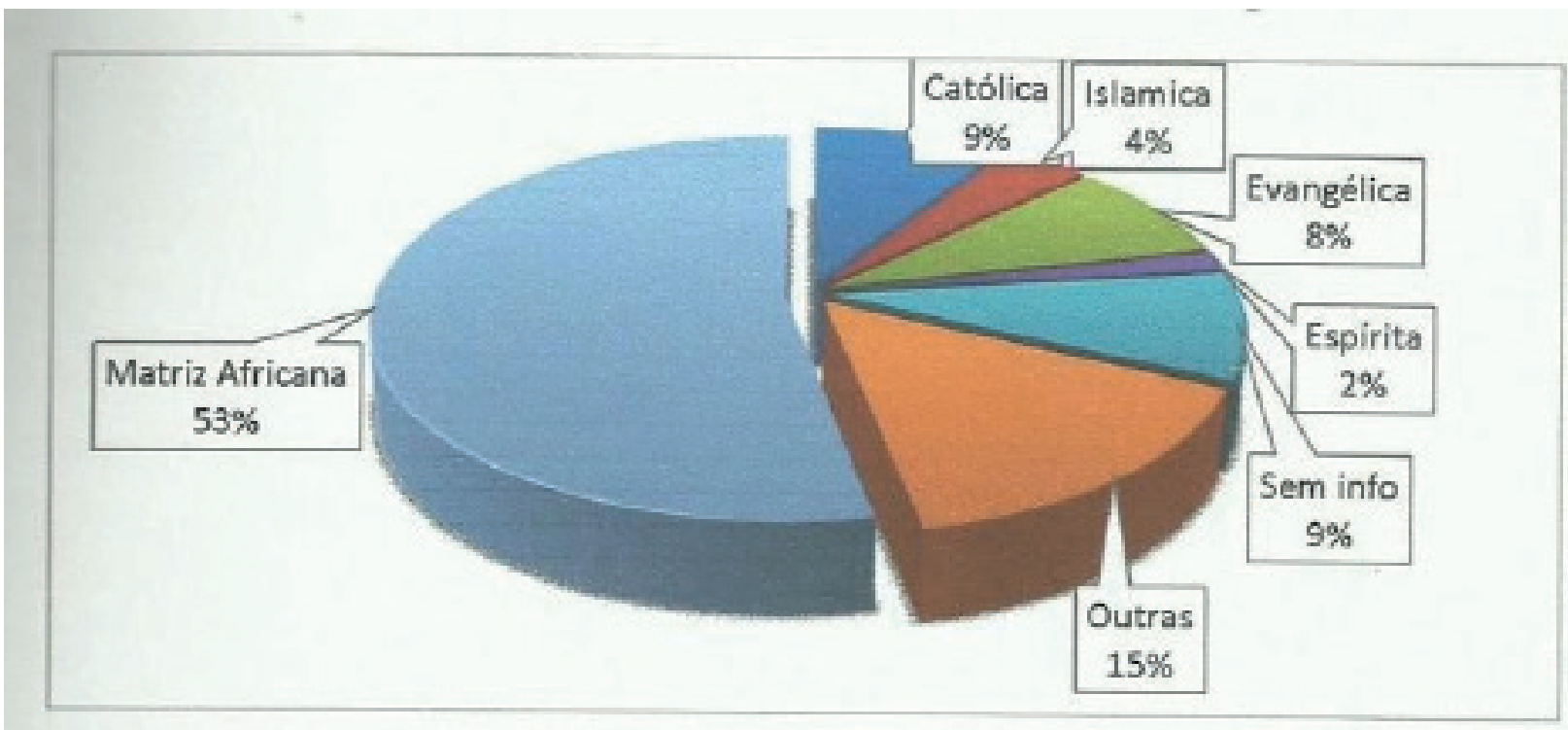

Fonte: RIVIR, $\mathrm{n}=409$

Fonte: RIVIR, 2016.

O relatório também faz referência a parcela dos agressores nas reportagens conforme gráfico 2.

GRÁFICO 2 - RELIGIÃO DOS AGRESSORES NAS REPORTAGENS

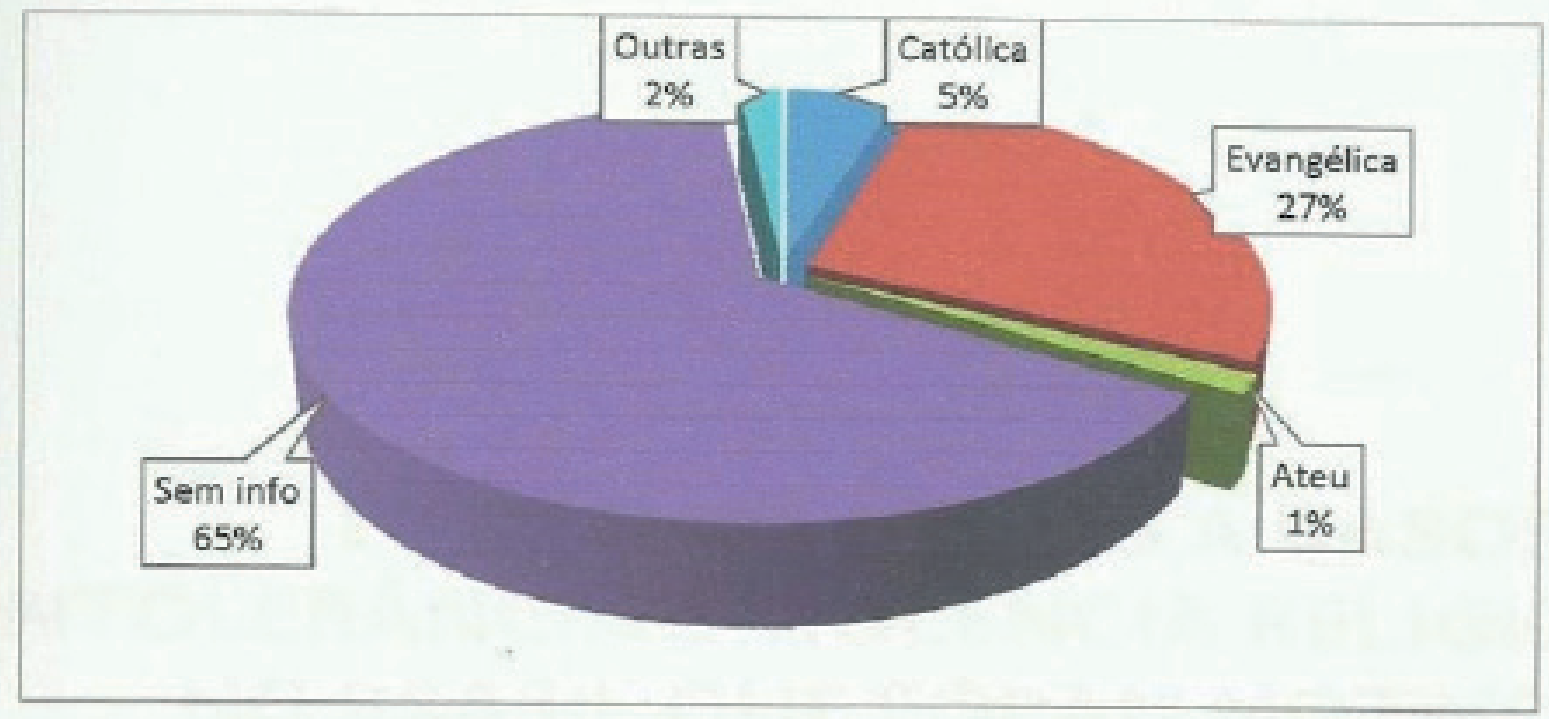

Fonte: RIVIR, $\mathrm{n}=409$ 


\section{autêntica}

DOI https://doi.org/10.31639/rbpfp.v\%vi\%i.251

De acordo com Silva (2015, p.9-10), no Brasil e outros países da América Latina, movimentos neopentecostais que são formados por adeptos oriundos das igrejas protestantes tradicionais como Luterana, Presbiteriana e Batista, assim como de outras religiões não evangélicas e fundamentadas numa teologia da prosperidade, estão cada vez menos tolerantes em relação às religiões afro-brasileiras.

Essa dificuldade de convivência das religiões neopentecostais com as religiões de matriz afro-brasileira, acreditamos que exista, entre outras razões, pelo motivo da cosmopercepção ${ }^{11}$ ou os elementos da filosofia africana e afro-brasileira irem de encontro à cultura hegemônica eurocêntrica construída ao longo do processo de colonização nas bases do capitalismo, do universalismo, da exclusão e do individualismo. Por outro lado, a cosmopercepção africana de mundo e do ser, está baseada no respeito mútuo, das diferenças e em uma prática religiosa inclusiva.

Portanto, quando se percebe a presença de um racismo epistemológico quanto aos saberes afrocentristas, percebe-se que há duas fortes justificativas, uma baseada em critérios religiosos, frutos de uma leitura teológica do Cristianismo, dentro de um momento da história e, outra, em critérios biológicos. A primeira tomou como base a maldição de Ham e, a segunda, na classificação dita científica, a partir de características físicas (cor de pele, traços morfológicos), estabeleceu-se uma relação de valores entre as chamadas raças. Estabeleceu-se uma relação intrínseca entre o biológico e qualidades psicológicas, morais, intelectuais e culturais.

Vale lembrar que, à época do Brasil colônia, os/as negros/as escravizados/as não possuíam liberdade religiosa e que o processo da escravidão estava diretamente relacionado com sua salvação, como bem mostra Saviane $(2013$, p.47) ao dizer que "[...] para os jesuítas a religião católica era considerada obra de Deus, enquanto as religiões dos índios e dos negros vindos da África eram obra do demônio".

Em linha com esse pensamento, Grosfoguel (2007, p.33) destaca que:

O privilégio epistêmico dos brancos foi consagrado e normalizado com a colonização das Américas no final do século XV. Desde renomear o mundo com a cosmologia cristã (Europa, África, Ásia e, mais tarde, América), caracterizando todo conhecimento ou saber não-cristão como produto do demônio, até assumir, a partir de seu provincianismo europeu, que somente pela tradição greco-romana, passando pelo renascimento, o iluminismo e as ciências ocidentais, é que se pode atingir a "verdade" e "universalidade", inferiorizando todas as tradições "outras" que no século XVI foram caracterizadas como "bárbaras", convertidas no século XIX em "primitivas", no século XX em "subdesenvolvidas" e no início do século XXI em "antidemocráticas" [...].

Observamos, na sociedade, uma grande valorização da cultura europeia em detrimento das culturas indígenas, africanas, ciganas e de outras etnias. Esse pensamento é confirmado por Gomes (2012, p. 102), quando elucida que:

[...] tal processo resultou na hegemonia de um conhecimento em detrimento de outro e a instauração de um imaginário que vê de forma hierarquizada e inferior as culturas, povos e grupos étnicosraciais que estão fora do paradigma considerado civilizado e culto, a saber, o eixo do Ocidente, ou o 'Norte' colonial.

11 Utilizamos o termo cosmopercepção ao invés de cosmovisão, apoiado nos estudos da pesquisadora nigeriana Oyèrónkẹ Oyěwùmí (1997), que em seu livro The invention of women: making an African sense of Western gender discourses informa que o termo cosmovisão reproduz a importância da visão no pensamento ocidental, razão pela qual o mundo é percebido principalmente pela visão. A diferenciação dos corpos humanos em termos de sexo, cor da pele e tamanho do crânio é um testemunho dos poderes atribuídos ao "ver". Na opinião da escritora, é eurocêntrico usar o termo cosmovisão para descrever culturas que podem privilegiar outros sentidos. O termo "cosmopercepção" é uma maneira mais inclusiva de descrever a concepção de mundo por diferentes grupos culturais, descrever os povos iorubás ou outras culturas que podem privilegiar sentidos que não sejam o visual ou, até mesmo, uma combinação de sentidos. 


\section{autêntica}

DOI https://doi.org/10.31639/rbpfp.v\%vi\%i.251

Para a implementação da Lei n. 10.629/2003, é necessário abordar a questão cultural dos povos africanos, mostrar outros conhecimentos que estão fora do eixo europeu. Nesse ponto, a gestão escolar tem um papel importante para fomentar ações dentro dos respectivos espaços escolares.

Em seu artigo, Macedo (2017, p.406), a partir de uma pesquisa realizada por Renísia Cristina Garcia-Filice, alerta-nos para comportamentos de ausência/alheamento por parte de alguns gestores/gestoras:

[...] gestão ausente/alheia que seriam as/os gestoras/es que em suas práticas cotidianas menosprezam ou acreditam ser insignificantes atitudes racistas, mesmo que de forma inconsciente. Logo, são alheias/os às necessidades de implementação da lei e pouco ou nada fazem para ver implementado o Artigo 26-A da Lei nº.10.639/2003. Dessas/es muitas/os se respaldam na convicção de que no Brasil, se vive uma democracia racial e não há conflitos dessa natureza.

Por outro lado, de forma positiva afirma Macedo $(2017$, p.407) que "há gestoras/es conscientes de seu papel [...] que, além de incluir a temática em seus projetos, incentivam a implementação de uma educação mais igualitária".

Porém, lamentavelmente, segundo a referida pesquisa, informa Macedo (2017, p. 407):

[...] mas infelizmente a maioria ainda é composta por aquelas/es que preferem fechar os olhos, se esconder atrás de práticas administrativas e fazer de conta que vivemos realmente uma democracia racial. E há também as/os que sabem da existência das leis antirracistas, assim como da oferta de formação para implementação das mesmas, mas por convicção da insignificância do tema, por ignorância ou ainda por falta de proatividade, deixam que cada qual, da equipe escolar, aborde a temática da maneira que achar mais conveniente - como observado neste trabalho.

Somando ao que já foi dito, acrescentamos também que, devido às convicções religiosas de muitos gestores e gestoras, professores e professoras, empecilhos são colocados ou simplesmente "não se toca no assunto" quanto a possibilidade de se trabalhar as questões africanas na escola.

Isto implica no trabalho que devemos realizar observando a Carta Magna: Constituição de 1988 que diz que o Estado é laico e que a intolerância religiosa é crime conforme a Lei $n^{\circ} .7 .716 / 89^{12} \mathrm{em}$ seu Art. 1: Serão punidos, na forma dessa Lei, os crimes resultantes de discriminação ou preconceito de raça, cor, etnia, religião ou procedência nacional.

\section{O ENSINO RELIGIOSO CONFESSIONAL NAS ESCOLAS PÚBLICAS}

Já que nosso artigo traz uma perspectiva interdisciplinar, achamos interessante, somado aos episódios anteriormente citados, refletir, em algumas linhas, a questão do ensino religioso. Primeiramente, trazemos ainda a recente decisão do Supremo Tribunal Federal ${ }^{13}$ (STF) que considerou constitucional o ensino público religioso confessional, que, possivelmente, abrirá espaço para o aumento dos casos de intolerância/racismo religioso nas escolas públicas com crianças de terreiro, porque, ao invés de congregar, educar para o diálogo inter-religioso e para a convivência com e entre os diferentes, essa decisão fomentará a discriminação entre aqueles que professam religiões diferentes das predominantes de origem cristã, ou até mesmo os que se dizem sem religião.

12 Disponível em: http://www.planalto.gov.br/Ccivil_03/LEIS/L7716.htm. Acesso em 09 jun.2019.

13 Votação que aconteceu no dia 27 de setembro de 2017. Por 6 votos a 5, os ministros do Supremo Tribunal Federal (STF) votaram pela manutenção do ensino religioso confessional. 


\section{autêntica}

DOI https://doi.org/10.31639/rbpfp.v\%vi\%i.251

A facultatividade do Ensino Religioso confessional, nas escolas, abrirá espaço para que denominações religiosas adentrem no espaço público escolar para doutrinar os seus seguidores com a liberação oficial do Estado, assim como, negligenciará o direito de outros terem acesso ao conhecimento da diversidade cultural de outros segmentos religiosos.

No dia 27 de setembro de 2017, o Supremo Tribunal Federal (STF) por 6 votos a 5, considerou constitucional o ensino religioso confessional, ou seja, vinculado a uma crença específica. Os ministros do supremo rejeitaram a ação da Procuradoria Geral da República para que as aulas fossem genéricas e abordassem aspectos históricos e sociais das religiões. Votaram contra o ensino religioso confessional os ministros Luís Alberto Barroso, Rosa Weber, Luiz Fux, Marco Aurélio e Celso de Mello. Pela manutenção do ensino confessional votaram a favor os ministros Alexandre de Moraes, Luiz Edson Fachin, Gilmar Mendes, Dias Toffoli, Ricardo Lewandowski e Cármem Lúcia que desempatou o caso.

Esses últimos alegaram que é possível pregar a religiosidade e crenças específicas em escolas públicas sem violar a laicidade do Estado. Mas uma pergunta fica no ar: quem são as religiões que terão esses espaços? As religiões donas de editoras e que possuem um grande acervo escrito ou aquelas religiões que se fundamentam na cultura oral, como as de origem afro-brasileiras?

Essa decisão do STF faz com que o Estado laico promova, nas escolas públicas, o ensino religioso confessional. Ao ensino religioso, estadual e municipal, vai ser permitido que toda religião possa adentrar a escola para doutrinamento religioso dos seus seguimentos. Abre-se um espaço para que as religiões hegemônicas se apropriem do espaço público escolar para propagar seus fundamentos de fé.

O ensino religioso voltado à uma determinada religião, ao invés de ter uma concepção de ensino que agregue, eduque para a convivência com os diferentes, agora, permitirá a segregação, a diferenciação e o aumento de casos de intolerância por motivos religiosos, algo que já era bem visível no espaço escolar.

Porém, no dia 15 de dezembro de 2017, no Conselho Nacional de Educação- CNE, o ensino religioso entrou na Base Nacional Comum Curricular ${ }^{14}$, não como catequese, mas como campo de conhecimento:

\footnotetext{
"O conhecimento religioso, objeto da área de Ensino Religioso, é produzido no âmbito das diferentes áreas do conhecimento científico das Ciências Humanas e Sociais, notadamente da(s) Ciência(s) da(s) Religião(ões). Essas Ciências investigam a manifestação dos fenômenos religiosos em diferentes culturas e sociedades enquanto um dos bens simbólicos resultantes da busca humana por respostas aos enigmas do mundo, da vida e da morte" (2017, p. 436).
}

Então, ainda que o STF diga que o ensino religioso pode até ser confessional, as diretrizes do MEC vão na direção da aprendizagem não confessional. Segundo o documento, os sistemas de ensino podem ampliar os conteúdos respeitando a diversidade regional e a Base deverá ser implementada pelas escolas brasileiras até o início do ano letivo de 2020, sendo revisada a cada cinco anos.

A base Nacional Comum Curricular traz contribuições para que se desenvolva uma cultura de paz nas escolas. Cultura essa como resultado do conhecimento e prática do respeito frente à pluralidade cultural e à diversidade religiosa existente em nosso país. Porém, na prática, observa-se a escola como palco de muitos 


\section{autêntica}

DOI https://doi.org/10.31639/rbpfp.v\%vi\%i.251

conflitos culturais e religiosos, ora por ter sido um espaço onde predomina a cultura europeia-judaico-cristã ora por ser um lugar que não está preparado para dialogar com o diferente e com as minorias culturais e religiosas. Uma escola que não dialoga está destinada a emudecer dentro da função que lhe compete.

Aproveitamos este espaço para fazer alguns questionamentos a partir dos quais esperamos levar os leitores a várias reflexões tais como:

Como ficarão os estudantes que são praticantes do Candomblé? E aqueles que professam outros credos? E os que não têm religião e acreditam em Deus? E os que não creem em nada? Como ficarão? E a inclusão das religiões de matriz africana e afro-brasileira na disciplina de ensino religioso? O ensino religioso confessional poderá acabar numa tentativa de doutrinação, de imposição dos postulados cristãos? Essa postura levará algum grau de inibição e/ou constrangimento às crianças de terreiro? Como se dará o combate da intolerância/ racismo religioso nas escolas? Continuaremos negando o reconhecimento da diversidade religiosa africana e afro-brasileira no Ensino Religioso em nosso Estado? Em nosso país?

\section{INTERDISCIPLINARIDADE: PONTES PARA A IMPLANTAÇÃO E APLICABILIDADE DA LEI No. 10.639/2003 NO ESPAÇO ESCOLAR}

A escola é um espaço que necessita ter atitudes interdisciplinares. Não negando a presença da diversidade cultural no ambiente escolar, é necessário que os/as docentes e os gestores e as gestoras procurem fazer um trabalho de diálogo com essa diversidade. A voz desse diálogo é o trabalho interdisciplinar. Abrindo-se o espaço escolar para todas as culturas, indica-se que nenhuma cultura se constitui em um lugar privilegiado a partir do qual podemos julgar as outras culturas. Cada cultura é a atualização de uma potencialidade do ser humano, em um lugar específico da terra e em um momento específico da história.

Fazenda $(2008$, p.8) informa que "[...] o processo interdisciplinar desempenha um papel decisivo no sentido de dar corpo ao sonho de fundar uma obra de educação à luz da sabedoria, da coragem e da humanidade", ou seja, sendo um desafio nos dias atuais, uma vez ultrapassado, pode trazer grandes benefícios para o processo de ensino-aprendizagem para professores e professoras e estudantes. O trabalho em conjunto, através de projetos, por exemplo, os docentes, nas várias disciplinas e a partir de um núcleo comum, podem trazer os conteúdos a serem trabalhados a partir da Lei 10.629/2003 para sala de aula.

Para isso alerta-nos Fazenda (2008, p. 13):

\footnotetext{
o primeiro passo para a aquisição conceitual interdisciplinar seria o abandono das posições acadêmicas prepotentes, unidirecionais e não rigorosas que fatalmente são restritivas, primitivas e "tacanhas", impeditivas de aberturas novas, camisas-de-força que acabam por restringir alguns olhares, tachando-os de menores. Necessitamos, para isso, exercitar nossa vontade para um olhar mais comprometido e atento às práticas pedagógicas rotineiras menos pretensiosas e arrogantes em que a educação se exerce com competência.
}

Assim, como resultado de um trabalho em conjunto, o exercício pedagógico da interdisciplinaridade pode trazer grandes resultados. A seguir, citaremos alguns livros e artigos que podem ajudar professores e professoras, em cada disciplina a trabalharem a temática afro-brasileira e, em especial, conhecimentos relacionados às religiões de Matriz Africana na escola. 


\section{autêntica}

DOI https://doi.org/10.31639/rbpfp.v\%vi\%i.251

No livro organizado por Renata Felinto Culturas africanas e afro-brasileiras em sala de aula- saberes para os professores- fazeres para os alunos (2012), há vários artigos que tratam a teoria e sugerem propostas metodológicas para a sala-de-aula para romper com o discurso hegemônico de poder, superar as diversas formas de desigualdade e desconstruir o racismo religioso.

Outro trabalho bem interessante é a obra de Rosa Margarida de Carvalho Rocha intitulada Educação das Relações Étnico-Raciais-pensando referenciais para a organização da prática pedagógica (2007), onde na segunda parte do livro ela traz tópicos para serem trabalhados de forma interdisciplinar através das disciplinas Artes, História, Ciências, Português, Educação Física, Língua Estrangeira, Geografia e Matemática.

Há um artigo de autoria de Nelson Fernando Inocêncio da Silva intitulado Africanidade e religiosidade: uma possibilidade de abordagem sobre as sagradas matrizes africanas na escola, no livro Educação anti-racista: caminhos abertos pela Lei Federal $n^{\circ} 10.639 / 03$ (2005) que faz uma reflexão sobre o porquê de se trabalhar a temática das religiões matriz africana na escola, assim como, a importância de se trazer concepções não eurocêntricas para a escola. Também é discutido sobre o ensino religioso no ambiente escolar entre outros assuntos.

O artigo de Douglas Verrangia intitulado Conhecimentos tradicionais de matriz africana e afro-brasileira no ensino de Ciência: um grande desafio (2010) propõe sugestões acerca desses conhecimentos e como eles podem ser abordados de forma positiva no ensino de Ciências.

Educação e meio ambiente são desvelados em dois trabalhos: por Denise Maria Botelho em Religiosidade afro-brasileira e o Meio Ambiente (2007); e por Felipe Rodrigues Martins em Educação Ambiental e Candomblé: afro-religiosidade como consciência ambiental (2015).

Henrique Cunha Junior em Candomblés: como abordar esta cultura na escola (2009), apresenta razões que justificam a apresentação das religiões africanas na educação brasileira além de discutir os racismos contra a população negra realizado na forma de informação religiosa.

Quanto ao ensino de Química, Anna M. Canavarro Benite, Morgana Abranches Bastos, Marysson J. R. Camargo, Regina N. Vargas, Geisa L. M. Lima e Claudio R.M. Benite em Ensino de Química e a Ciência de Matriz Africana: Uma Discussão Sobre as Propriedades Metálicas (2007), envolvem uma discussão com alunos sobre racismo, as raízes históricas do racismo no Brasil a partir da diáspora africana e os conceitos envolvidos no estudo das propriedades dos metais, contribuindo para a implementação da lei n. 10.639/03 no ensino de Química. Interessante se fazer uma inter-relação, nesse estudo, com o Orixá Ogum ${ }^{15}$, que concedeu aos seres humanos o segredo da forja do ferro: $O$ ferro é o elemento químico mais abundante na crosta terrestre e sua importância é destacada pela sua utilização em várias atividades humanas.

15 Segundo a cosmologia iorubana, Ogum, é o orixá responsável pelas ferramentas. Para cada atividade, Ogum é capaz de trazer a ferramenta adequada para conseguir o objetivo desejado. É o que tem a responsabilidade de trazer em si o conhecimento tecnológico. 


\section{autêntica}

DOI https://doi.org/10.31639/rbpfp.v\%vi\%i.251

\section{CONSIDERAÇÕES FINAIS}

Neste trabalho, trouxemos algumas contribuições ao elencar artigos e livros que podem ajudar professores e professoras a trabalharem a temática afro-brasileira e, de modo particular, temas relacionados às religiões de Matriz Africana na escola.

Percebemos a necessidade urgente de termos uma educação anti-racista, para isso, precisamos abraçar a tarefa da educação das relações étnico-raciais todos os 365 dias do ano.

Precisamos de políticas públicas, ou seja, a intervenção do Estado em ações para o cumprimento das leis já existentes e quanto aos atos de intolerância/ racismo religioso nas escolas. Precisamos de ações afirmativas, ou seja, de ações dos movimentos sociais até as pequenas ações ocorridas dentro da sala de aula.

Negros e negras, povos que contribuíram para o desenvolvimento econômico do nosso país, não podem ficar invisibilizados no cotidiano social, por ser uma questão de justiça social e epistemológica. Seus protagonismos são apenas conhecidos no processo de escravização, mostrados através de imagens dos livros didáticos e filmes.

Assinala Arroyo (2010, p.1383) que,

Corrigir as desigualdades educacionais perpassa as justificativas de todas as políticas. Mostrar o pouco que se avançou, se retrocedemos e o que planejar, que estratégias e que intervenções no sistema escolar, na formação docente para corrigir as desigualdades no próximo decênio. $O$ fantasma dessas desigualdades perturbando nossos sonhos de República, de democracia, de justiça e equidade. Talvez seja a relação mais persistente tanto no pensamento conservador ou liberal, como no progressista. Porque as desigualdades continuam persistentes. Incômodas. Uma relação que tem instigado pesquisas, teses, dissertações, produção teórica, mostrando a diversidade de fatores determinantes de sua persistência.

Não podemos olvidar das contribuições que vários escritores negros e várias escritoras negras, cientistas, poetas e poetizas, etc. deram para o desenvolvimento e formação da sociedade brasileira. Informar as crianças, os/as adolescentes e os/as jovens negros/negras que eles/elas podem ser protagonistas de suas próprias histórias. Hoje, diante do quadro político que estamos vivenciando em nosso país, necessitamos de produções acadêmicas para conhecermos as desigualdades históricas que condicionaram desigualdades educacionais por décadas em nossa sociedade. "Enquanto não mudarmos o modo de pensar os desiguais como problema, não mudaremos a visão do Estado e de suas políticas como a solução" (ARROYO, 2010, p. 1388).

Que o Ensino Religioso aconteça a partir de pressupostos éticos e científicos, sem privilégio de nenhuma crença ou convicção. Isso implica abordar esses conhecimentos com base nas diversas culturas e tradições religiosas, sem desconsiderar a existência de filosofias seculares de vida. Acreditamos que o ensino religioso, ao trabalhar com princípios éticos, colaborará com a ideia de que "pensar não é tudo, porque além de agir nós temos que sentir, nós temos que criar formas de pensamento que sejam mais acolhedoras às emoções, ao corpo, aos afetos, aos sentimentos" (Santos, 2001, p. 20).

O trabalho de implementação e implantação da Lei n. 10.639/2003, através de uma abordagem interdisciplinar, quer seja feito nas escolas contemplando a diversidade existente nesses espaços, quer desmistificando 


\section{autêntica}

DOI https://doi.org/10.31639/rbpfp.v\%vi\%i.251

a ideia de demonização dos conhecimentos espirituais e éticos oriundos do continente africano, ajudará na desconstrução do racismo epistêmico/religioso no ambiente escolar. A partir de novos olhares e posturas diante dos conhecimentos trazidos pelas religiões de Matrizes Africanas e de seus adeptos, possamos criar novos comportamentos baseados no direito, no respeito às diferenças, para construção de um mundo mais justo e feliz.

Informa Arroyo (2015, p. 22) que,

Esse apego a reduzir o direito à educação e os direitos humanos a indivíduos e o dever do Estado apenas com os indivíduos não tem acompanhado o avanço de abundantes declarações em defesa dos direitos coletivos da própria Assembleia Geral das Nações Unidas por direitos humanos, orientação sexual e identidade de gênero, pela eliminação de todas as formas de discriminação racial, pelo direito de autodeterminação dos povos indígenas etc.

Além disso, a ONU- Organização das Nações Unidas ao proclamar na resolução n. 68/237, em 19 de dezembro de 201316, a década Internacional de Afrodescendentes entre 2015 e 2024, destaca a importante contribuição dada pelas e pelos afrodescendentes para nossas sociedades e propõe medidas concretas para promover a sua plena inclusão, o combate ao racismo, à discriminação racial, à xenofobia e à intolerância. 


\section{autêntica}

DOI https://doi.org/10.31639/rbpfp.v\%vi\%i.251

\section{REFERÊNCIAS}

ARROYO, Miguel. Políticas educacionais e desigualdades: à procura de novos significados. Educação \& Sociedade, Campinas, v. 31, n. 113, p. 1381-1416, out./dez.2010.

O direito á educação e a nova segregação social e racial - tempos insatisfatórios. Educação em Revista \& Sociedade, Belo Horizonte, v. 31, n. 83, p. 15-47, jul./set,.2015.

BASTOS, Morgana A. et al. Ensino de Química e a Ciência de Matriz Africana: uma discussão sobre as propriedades dos metais. XVII Encontro Nacional de Ensino de Química, Ouro Preto, 20 Ambiental: UNESCO, 2007.

BOTELHO, Denise Maria. Religiosidade afro-brasileira e o meio ambiente. In: Vamos cuidar do Brasil: conceitos e práticas em educação ambiental na escola [Coordenação: Soraia Silva de Mello, Rachel Trajber]. Brasília: Ministério da Educação, Coordenação Geral de Educação Ambiental: Ministério do Meio Ambiente, Departamento de Educação Ambiental: UNESCO, 2007.

NASCIMENTO, W. F. do. Educação e religiosidades afro-brasileiras: a experiência dos candomblés. Participação, Brasília, n. 17, jan. 2012.

BRASIL. Ministério da Educação. Secretaria da Educação Básica. Base nacional comum curricular. Brasília, DF, 2017.

CUNHA JUNIOR, Henrique. Candomblé: como abordar esta cultura na escola. Revista Espaço Acadêmico, n.102, ano IX, p. 97-103, nov. 2009.

FAZENDA, Ivani, Catarina Arantes. (Org.). Didática e Interdisciplinaridade. 13ª ed. Campinas, SP: Papirus, 2008.

FELINTO, Renata. (Org.). Culturas africanas e afro-brasileiras em sala de aula- saberes para os professoresfazeres para os alunos. Belo Horizonte: Fino Traço Editora, 2012.

FERNANDES, Nathalia Vince Esgalha. A Raiz do Pensamento Colonial na Intolerância Religiosa Contra Religiões de Matriz Africana. Revista Calundu, Brasília, vol. 1, n.1, p.117-136, jan./jun. 2017.

GARCIA-FILICE, Renísia Cristina. Raça e classe na gestão da educação básica brasileira. 2010. Tese (Doutorado em Educação) - Universidade de Brasília, Brasília, 2010

GOMES, N. L. Relações étnico-raciais, educação e descolonização dos currículos. Currículo sem Fronteiras, v. 12, p. $98-109,2012$

GROSFOGUEL, R. Dilemas dos estudos étnicos norte-americanos: multiculturalismo identitário, colonização disciplinar e epistemologias descoloniais. Ciência e Cultura, São Paulo, v. 59, n. 2, abr./jun. 2007, pp. 32-35.

Para descolonizar os estudos de economia política e os estudos pós-coloniais: transmodernidade, pensamento de fronteira e colonialidade global. Revista Periferia, Rio de Janeiro, v. 1, n. 2, p. 41-91, jul./dez. 2009. 


\section{autêntica}

DOI https://doi.org/10.31639/rbpfp.v\%vi\%i.251

MACEDO, Aldenora. Negar, silenciar, apaga: a gestão escolar frente à educação antirracista. Revista da ABPN - v. 9, n. 22, , p.385-408, mar/jun 2017.

MARTINS, Felipe Rodrigues. EDUCAÇÃO AMBIENTAL E CANDOMBLÉ: AFRO-RELIGIOSIDADE COMO CONSCIÊNCIA AMBIENTAL" Environmental Education and Candomble: african religiosity as environmental awareness".' PARALELLUS Revista de Estudos de Religião-UNICAP 6.12 (2015): 265-278.

MATTOS, Regiane Augusto de. História e cultura afro-brasileira. 1. ed. São Paulo: Contexto, 2009.

OYEWUMI, O. The invention of women: making an African sense of Western gender discourses. Minneapolis, MN: University of Minnesota Press, 1997.

QUIJANO. Anibal. Colonialidad y Modernidad/Racionalidad. Peru Indígena, Lima, v. 13, n.29, p.11-20, 1992.

Raza, etnia y nación en Mariátegui: cuestiones abiertas. Estudios latinoamericanos, v. 2, n. 3, p. 3-19, 1995.

Colonialidade do Poder, Eurocentrismo e América Latina. In. LANDER, E. (org.). A Colonialidade do Saber: eurocentrismo e Ciências Sociais. Trad. Júlio César Casarin Barroso Silva. 3. ed., Buenos Aires: CLACSO, 2005, p. 227-278.

Colonialidade do poder e Classificação Social. In: SANTOS, Boaventura de Sousa; MENESES, Maria Paula. Epistemologias do Sul. Coimbra: Edições Almedina SA, 2009, p. 119-131.

ROCHA, Rosa Margarida de Carvalho. Educação das Relações Étnico-Raciais-pensando referenciais para a organização da prática pedagógica. Belo Horizonte: Mazza Edições, 2007.

SAVIANE, Dermeval. História das ideias pedagógicas no Brasil. 4. ed. Campinas, SP: Autores Associados, 2013.

SANTANA, Jair. A lei n $n^{0}$ 10.639/03 e o ensino de artes nas séries iniciais: políticas afirmativas e folclorização racista. Tese (Doutorado em Educação) - Universidade Federal do Paraná, Paraná, 2010.

SANTOS, Boaventura de Sousa. Para além do pensamento abissal: das linhas globais a uma ecologia de saberes. In: SANTOS, Boaventura de Sousa e MENEZES, Maria Paula (Org.). Epistemologias do Sul. Coimbra: Ed. Almedina, 2009.

Seis Razões parar pensar. Lua Nova: Revista de Cultura e Política, São Paulo, n. 54, p. 13-26, 2001. Disponível em: <http://www.scielo.br/pdf/In/n54/a03n54.pdf>. Acesso em: 12 maio. 2017.

SILVA, Nelson Fernando Inocêncio da. Africanidade e religiosidade: uma possibilidade de abordagem sobre as sagradas matrizes africanas na escola. In. Educação anti-racista: caminhos abertos pela Lei Federal $n^{\circ}$ 10.639/03. Secretaria de Educação Continuada, Alfabetização e Diversidade. Brasília: Ministério da Educação, 2005.

SILVA, Vagner Gonçalves da (Org.). Intolerância Religiosa: impactos do neopentecostalismo no campo religioso afro-brasileiro. 1.ed. São Paulo: Editora da Universidade de SÃO Paulo, 2015. 


\section{autêntica}

DOI https://doi.org/10.31639/rbpfp.v\%vi\%i.251

SILVA, José Antonio Novaes da. Conquista de direitos, ensino de ciências/biologia e a prática da sangria entre os/as Remetu-Kemi e povos da região congo/angola: uma proposta de articulação para a sala de aula. Revista da Associação Brasileira de Pesquisadores/as Negros/as (ABPN), [S.I.], v. 9, n. 22, p. 149-175, jun. 2017. ISSN 2177-2770.

VERRANGIA, Douglas. Conhecimentos tradicionais de matriz africana e afro-brasileira no ensino de Ciências: um grande desafio. Revista África e Africanidades, v. 8, 2010, p. 14.

VERRANGIA, Douglas; SILVA, Petronilha Beatriz Gonçalves e. Cidadania, relações étnicoraciais e Educação: desafios e potencialidades do ensino de Ciências. Educação e Pesquisa (USP. Impresso), v. 36. São Paulo: 2010, p. 705-718

RIVIR - Relatório sobre Violência Religiosas e Intolerância no Brasil (2011-2015). Resultados Preliminares. Brasília: Secretaria Especial de Direitos Humanos do Ministério das Mulheres, da Igualdade racial, da juventude e dos Direitos Humanos, 2016.

FILIZOLA, G. J.; BOTELHO, D. M.;

Lei 10.639/2003: caminhos para desconstrução do racismo epistêmico/religioso no ambiente escolar Formação Docente - Revista Brasileira de Pesquisa sobre Formação de Professores

Vol. 11, no. 22 (p. 59-78) 31 dez. 2019 
